\title{
GENETIC POLYMORPHISM OF THE A SUBUNIT OF HUMAN COAGULATION FACTOR XIII IN JAPANESE
}

\author{
Toshinori NishigakI, ${ }^{1}$ Keiichi OMoto, ${ }^{1}$ and Takeo JuJI ${ }^{2}$ \\ ${ }^{1}$ Department of Anthropology, Faculty of Science, The University of Tokyo, \\ Tokyo 113, Japan \\ 2Blood Transfusion Service, Tokyo Women's Medical College, \\ Tokyo 160, Japan
}

\begin{abstract}
Summary Polymorphism of the A subunit of human coagulation factor XIII was investigated in a total of 561 plasma samples from unrelated adult Japanese using an agarose gel electrophoresis followed by a fluorescent technique for the localization of transglutaminase activity. Three common phenotypes were observed, which corresponded to the types 1, 2-1 and 2 reported by Board (1979) in Australians. The family material from 23 matings with 60 children indicated that these phenotypes are controlled by a pair of autosomal, codominant alleles. The estimated allele frequencies of $F 13 A^{*} 1$ and $F 13 A^{*} 2$ were 0.887 and 0.113 , respectively.
\end{abstract}

\section{INTRODUCTION}

Factor XIII is the precursor of the transamidating enzyme, fibrinoligase, which is responsible for the covalent crosslinking of fibrin molecules in the final stage of the blood coagulation process (Folk and Chung, 1973). It is known that the factor XIII protein from human plasma is a tetramer composed of two different subunits, A and $\mathrm{B}$. In the presence of thrombin and $\mathrm{Ca}^{2+}$, the activated protein is cleaved into the enzymatic A subunit and the non-enzymatic B subunit (Schwartz et al., 1973).

Genetic polymorphism of the A subunit of factor XIII was recently demonstrated in Australian Caucasians (Board, 1979). Three phenotypes (1, 2-1 and 2) were distinguishable by an agarose gel electrophoresis followed by a fluorescent technique for localization of transglutaminase activity. The phenotypes were shown to be controlled by a pair of autosomal, codominant alleles.

Few studies have been reported as to this polymorphism in population groups other than Caucasians. Recently, Kera and Nishimukai (in press) investigated a sample of Japanese using isoelectric focusing followed by immunofixation. They also reported three phenotypes which they referred to as type 1, 2-1 and 2. In this paper, we report the results of our investigation in which the Board's original method fo rtyping was adopted.

Received July 3, 1981 


\section{MATERIALS AND METHODS}

The family material consisting of 23 matings with 60 children was obtained in Tokyo. A total of 561 plasma samples from 515 unrelated blood donors and 46 parents of the family material were used for population study. Samples for typing were either heparinized or ACD plasma, and were stored at $-30^{\circ} \mathrm{C}$ until use.

An agarose gel electrophoresis was carried out using the method of Board (1979) with slight modifications. A glass plate $(180 \times 180 \times 1.2 \mathrm{~mm})$ was covered with a $1.4 \mathrm{~mm}$ thick layer of $1 \%(\mathrm{w} / \mathrm{v})$ agarose gel made with the gel buffer. The electrode buffer contained $29 \mathrm{~mm}$ lithium hydroxide and $191 \mathrm{~mm}$ boric acid, adjusted to $\mathrm{pH} 8.45$. The gel buffer was prepared by combining 90 vol. solution containing $5.71 \mathrm{~mm}$ citric acid and $52 \mathrm{~mm}$ tris(hydroxymethyl)aminomethane with 10 vol. electrode buffer, adjusted to $\mathrm{pH} 8.65$ (Ashton and Braden, 1961). Electrophoresis was carried out between the cooling plates at $18 \mathrm{~V} / \mathrm{cm}$ until a hemoglobin marker migrated at least $6.5 \mathrm{~cm}$ from the origin.

Detection of the location of transglutaminase activity was essentially following the method described by Board (1979). The gel was overlaid with a filter paper (Toyo No. 1) soaked in the following reaction mixture: $1 \mathrm{ml} 1 \mathrm{M}$ Tris- $\mathrm{HCl}(\mathrm{pH} \mathrm{8.0)}$; $1 \mathrm{ml} 0.05 \mathrm{M} \mathrm{CaCl}_{2} ; 3 \mathrm{ml}$ casein (acc. to Hammarsten, Wako Pure Chemical, Osaka, Japan) $10 \mathrm{mg} / \mathrm{ml}$ dissolved in $0.2 \mathrm{M}$ Tris- $\mathrm{HCl}(\mathrm{pH} 8.0) ; 1 \mathrm{ml} 0.025 \mathrm{M}$ monodansyl cadaverine; $20 \mu 1 \quad \beta$-mercaptoethanol; $c a .10 \mathrm{U}$ human thrombin (Green Cross, Osaka, Japan).

Monodansyl cadaverine was initially dissolved in a small amount of $0.1 \mathrm{M} \mathrm{HCl}$ and then the volume was made up with $0.1 \mathrm{M}$ Tris- $\mathrm{HCl}(\mathrm{pH} 8.0)$. The gel was then incubated at $37^{\circ} \mathrm{C}$ for $12-15 \mathrm{hr}$ in a moist chamber. After incubation, the filter paper was removed and the gel was fixed for $5 \mathrm{~min}$ using a sheet of filter paper soaked in $7.5 \%(\mathrm{w} / \mathrm{v})$ trichloroacetic acid. After fixing, the gel was again overlaid for $5 \mathrm{~min}$ with another filter paper soaked in $0.3 \mathrm{M} \mathrm{Na}_{2} \mathrm{HPO}_{4}$. The gel was subsequently washed under running tap water for 1-2 hr to remove the unincorporated monodansyl cadaverine, and then the location of transglutaminase activity was detected under UV light (long wave).

\section{RESULTS AND DISCUSSION}

Three different patterns were observed by the electrophoretic screening of plasma samples for population study (Fig. 1). Those patterns are characteristic of the electrophoretic variation of a dimeric protein with two alleles. For example, the pattern of type 2-1 consists of three bands with the intermediate, presumably heterodimeric band stained stronger than the others.

Board (1979) proposed to refer to this system as the $F-X I I I$ locus with two alleles termed $F-X I I I^{1}$ and $F-X I I I^{2}$. Later, however, he demonstrated a genetic 


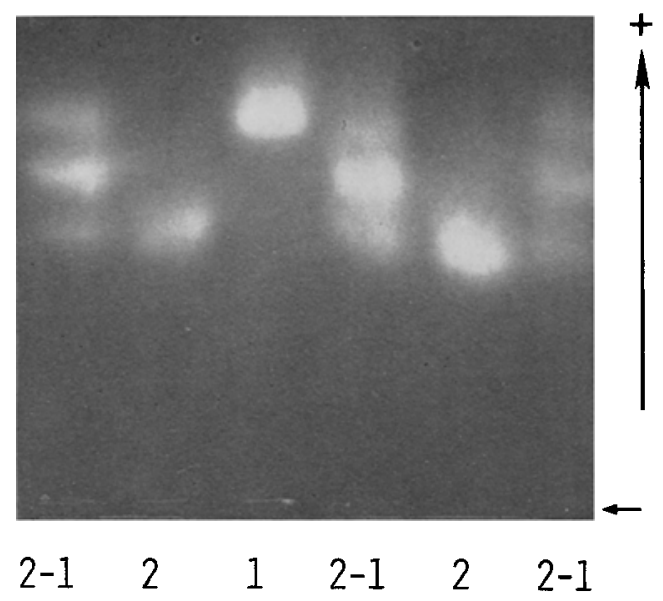

Fig. 1. Photograph showing electrophoretic patterns of three phenotypes of the A subunit of factor XIII. The small arrow indicates the place of sample application.

polymorphism of the $\mathrm{B}$ subunit of factor XIII, which was controlled by $F-X I I I B$ locus with three alleles (Board, 1980). To avoid confusion, we adopt a symbol, $F 13 A$ to refer to the structural locus controlling the A subunit of factor XIII, $F 13 A^{*} 1$ and $F 13 A^{*} 2$ standing for two alleles according to the International System for Human Gene Nomenclature (Shows et al., 1979). F13A*1 controls the fast component and $F 13 A^{*} 2$ controls the slow component. In order to identify the phenotypes with those reported by Board (1979), plasma samples from Caucasoid individuals living in Tokyo were used in comparison runs. The three phenotypic patterns observed in Japanese and Caucasians were identical. No rare variant was detected in the present Japanese sample.

Investigation was also carried out in a family material (Table 1, Fig. 2). The result was consistent with the hypothesis that this polymorphism is controlled by two codominant alleles, $F 13 A^{*} 1$ and $F 13 A^{*}$, at an autosomal locus.

The mode of inheritance of a congenital factor XIII deficiency has been reported. Possibility of a sex-linkage was suggested (Hampton et al., 1966; Ratnoff and Steinberg, 1968), although recent reports indicated an autosomal ressesive inheritance (MacDonagh et al., 1971; Losowsky and Miloszewski, 1977; Barbui et al., 1978). The result of the present family study obviously indicates that the structural gene of the A subunit is on an autosomal chromosome.

The distribution of phenotypes and allele frequencies in the present study are shown in Table 2. The observed numbers of phenotypes were in good agreement with the numbers expected on the basis of Hardy-Weinberg's law. The allele frequencies of $F 13 A^{*} 1$ and $F 13 A^{*} 2$ were estimated at 0.887 and 0.113 , respectively. These allele frequencies do not differ significantly from those observed in another study on Japanese population (Kyoto City) using the method quite different from 
Table 1. Factor XIII-A phenotypes in 23 families with 60 children.

\begin{tabular}{lcccc}
\hline & No. families & \multicolumn{3}{c}{ Offspring types } \\
Parental types & 12 & $1-1$ & $2-1$ & $2-2$ \\
\hline $1-1 \times 1-1$ & 9 & 30 & 0 & 0 \\
$1-1 \times 2-1$ & 2 & 15 & 9 & 0 \\
$2-1 \times 2-1$ & 1 & 4 & 1 \\
\hline
\end{tabular}
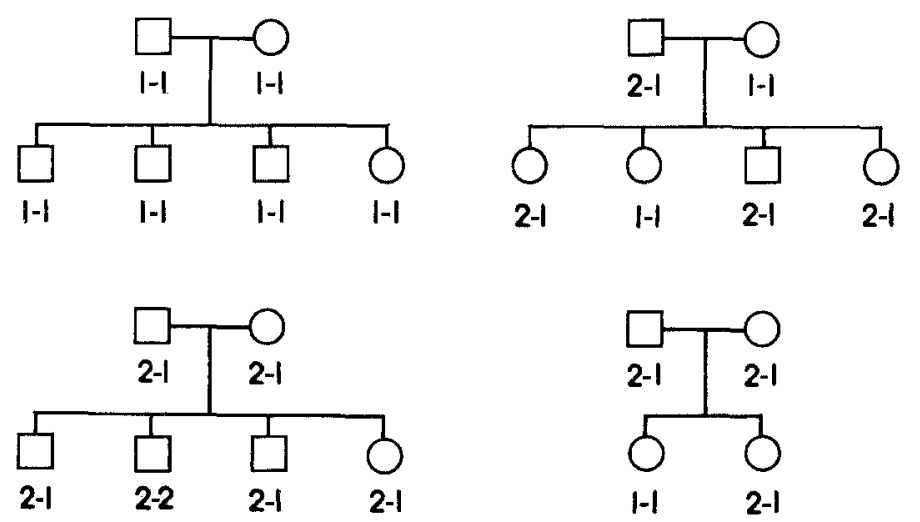

Fig. 2. Examples of families showing inheritance of factor XIII-A.

Table 2. Distribution of factor XIII-A phenotypes and allele frequencies in a Japanese population.

\begin{tabular}{lcccc} 
& & Phenotypes & & Total \\
& -1 & $2-1$ & 2 & 561 \\
\hline Obs. No. & 441 & 113 & 7 & \\
Exp. No. & 441.4 & 112.5 & 7.2 & \\
\hline
\end{tabular}

$\chi^{2}=0.008$, d.f. $=1, \mathrm{p}>0.9$.

Allele frequencies: $\quad F 13 A^{*} 1=0.887, F 13 A^{*} 2=0.113$.

Table 3. Allele frequencies of factor XIII-A in various populations.

\begin{tabular}{lcccl}
\hline Population & $\mathrm{N}$ & $F 13 A^{*} l$ & $F 13 A^{*} 2$ & \multicolumn{1}{c}{ Authors } \\
\hline Australian & $179^{\mathrm{a}}$ & 0.79 & 0.21 & Board (1979) \\
Australian & $204^{\mathrm{b}}$ & 0.80 & 0.20 & Board (1979) \\
Japanese & $250^{\mathrm{a}}$ & 0.90 & 0.10 & Kera et al. (in press) \\
Japanese & $56^{\mathrm{a}}$ & 0.89 & 0.11 & present study \\
\hline
\end{tabular}

a. Determined from plasma, $b$ determined from expired platelets. 
that of Board (1979), namely, the agarose gel isoelectric focusing followed by immunofixation (Kera and Nishimukai, in press). The allele frequency of $F 13 A^{*} I$ in the Japanese population appears to be higher than that in the Caucasian population (Table 3), so far as the limited data available now are concerned.

Since the technique for determining phenotypes is relatively easy and inexpensive, genetic polymorphism of the A subunit of factor XIII is a useful marker in human genetics for population studies.

Acknowledgment We wish to express our gratitudes to Mr M. Uchikawa, Blood Transfusion Service, Tokyo University Hospital and Mr K. Tokunaga in our laboratory for providing us with blood samples.

\section{REFERENCES}

Ashton, G.C., and Braden, A.W.H. 1961. Serum $\beta$ globulin polymorphism in mice. Aust. J. Biol. Sci. 14: 248-253.

Barbui, T., Rodeghiero, F., Dini, E., Mariani, G., Papa, M.L., DeBiasi, R., Cordero-Murillo, R., and Montero-Umana, C. 1978. Subunits $A$ and $S$ inheritance in four families with congenital Factor XIII deficiency. Br. J. Haematol. 38: 267-271.

Board, P.S. 1979. Genetic polymorphism of the A subunit of human coagulation factor XIII. Am. J. Hum. Genet. 31: 116-124.

Board, P.S. 1980. Genetic polymorphism of the B subunit of human coagulation factor XIII. Am. J. Hum. Genet. 32: 348-353.

Folk, J.E., and Chung, S.I. 1973. Molecular and catalytic properties of transglutaminases. $A d-$ vances in Enzymology 38: 110-191.

Hampton, J.W., Cunningham, G.R., and Bird, R.M. 1966. The pattern of inheritance of defective fibrinase (Factor XIII). J. Lab. Clin. Med. 67: 914-921.

Kera, Y., and Nishimukai, H. Genetic polymorphism of the A subunit of human coagulation factor XIII in Japanese. Hum. Hered. (in press).

Losowsky, M.S., and Miloszewski, K.J.A. 1977. Factor XIII. Br. J. Haematol. 37: 1-5.

McDonagh, J., McDonagh, R.P., Jr., and Duckert, F. 1971. Genetic aspects of Factor XIII deficiency. Ann. Hum. Genet. (Lond.) 35: 197-205.

Ratnoff, O.D., and Steinberg, A.G. 1968. Inheritance of fibrin-stabilizing-factor deficiency. Lancet 1: $25-26$.

Schwartz, M.L., Pizzo, S.V., Hill, R.L., and MuKee, P.A. 1973. Human factor XIII from plasma and platelets; Molecular weights, subunit structure, proteolytic activation and cross-linking of fibrinogen and fibrin. J. Biol. Chem. 248: 1395-1407.

Shows, T.B., Alper, C.A., Bootsma, D., Dorf, M., Douglas, T., Huisman, T., Kit, S., Klinger, H.P., Kozak, C., Lalley, P.A., Lindsley, D., McAlpine, J.K., McDougall, J.K., Meera Khan, P., Meisler, M., Morton, N.E., Opitz, J.M., Partridge, C.W., Payne, R., Roderick, T.H., Rubinstein, P., Ruddle, F.H., Shaw, M., Spranger, J.W., and Weiss, K. 1979. International system for human gene nomenclature (1979) ISGN (1979). Cytogenet. Cell Genet. 25: 96-116. 